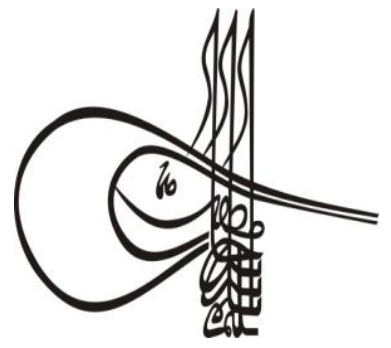

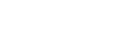

\section{Turkish Studies \\ Language and Literature \\ Volume 14 Issue 2, 2019, p. 995-1011 \\ DOI: 10.29228/TurkishStudies.22917 \\ ISSN: 2667-5641 \\ Skopje/MACEDONIA-Ankara/TURKEY}

ResearchArticle / Araştırma Makalesi

ArticleInfo/MakaleBilgisi

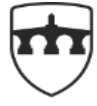

INTERNATIONAL

BALKAN

UNIVERSITY

EXCELLENCE FOR THE FUTURE IBU.EDU.MK

Received/Geliş: 06.04.2019

Gor Report Dates/Rapor Tarihleri: Referee 1 (28.04.2019)-Referee 2 (02.05.2019)

This article was checked by iThenticate.

\title{
"el-YÂSEMÎN" İSİMLİ ARAPÇA EĞİTİM SETİNİN DİLBİLGİSİ ÖĞRETİM YÖNTEMİ AÇISINDAN DEĞERLENDİRİLMESİ
}

\author{
Hact YILMAZ*
}

\begin{abstract}
ÖZ
Bu çalışmada, 2017 yılında Birleşik Arap Emirlikleri'nde basılan ve bir öğrenci kitabıyla bir alıştırma kitabı olmak üzere iki kitaptan oluşan "el-Yâsemîn" isimli Arapça öğretim setinin dilbilgisi konuları ve konuları işleme metodu üzerinde durulmuştur. Set, ilk defa Ankara Yıldırım Beyazıt Üniversitesi, İnsan ve Toplum Bilimleri Fakültesi, Arapça Mütercim-Tercümanlık Anabilim Dalı'nın hazırlık sınıfında, 2018-2019 öğretim yılında okutulmaya başlanmıştır. Çalışmanın amacı, adı geçen setteki dilbilgisi öğretim yöntemini ortaya koymak suretiyle bundan sonra bu seti okutacak ve okuyacak öğretmenlere ve öğrencilere bu konuda bir fikir vermektir. İnceleme setin mevcut iki kitabıyla sınırlandırılmıştır. Çalışmada nitel araştırma yöntemi kullanılmış, elde edilen veriler toplanarak analize edilmiştir.

Sonuç olarak, "el-Yâsemîn" Arapça öğretim seti, dilbilgisi konularının seçimi ve konuları ele alış şekli açısından başarılı bulunmuştur. Özellikle setin sarmal öğrenme yaklaşımını etkili bir şekilde kullanması dikkat çekmektedir. Setin iletişimsel bir metot benimsemesi, dilbilgisi konularını işleyişine de yansımakta ve güncel örnekler vererek kelimelerin akılda kalmasını sağlamaktadır. Konuların tam olarak bitmesi ve anlaşılması setin bütün aşamalarının bitmesiyle mümkün olacağından bazı konuları kavramak için setin düzeylerinin tamamının bitmesi beklenmelidir. Çünkü setin hazırlanmasında, özelden genele ya da olaylardan yasalara geçiş şeklindeki akıl yürütmek anlamına gelen tümevarım yöntemi benimsenmiștir. Kanaatimizce bu setin gramer konuları sınıf ortamında iyi bir şekilde işlenirse başka bir gramer litabı okutulmasına gerek kalmayacaktır.
\end{abstract}

Anahtar Kelimeler: "el-Yâsemîn” Eğitim Seti, Gramer Eğitimi, Metot, Kitap İnceleme, Kitap Değerlendirme. 


\title{
EVALUATION OF VIEWPOINT GRAMER TEACHING METHOD
} OFEDUCATION SET NAMED AS “el-YÂSEMÎN"

\begin{abstract}
This study focused on the grammar of the Arabic teaching set "ALJasmine", which was published in the United Arab Emirates in 2017 and consists of two books, one student book and one exercise book, and the method of processing topics. Set, for the first time, Ankara Yildirim Beyazit University, Faculty of human and Social Sciences, Arabic translation and interpreting Department's preparatory class, 2018-2019 academic year has been started to be taught. The aim of the study is to give an idea to the teachers and students who will read and read this set after this by revealing the grammar teaching method in the mentioned set. The review is limited to the two existing books of the set. Qualitative research method was used in the study and the data obtained were collected and analyzed.

As a result, the" El-Jasmine " Arabic teaching set has been found to be successful in terms of the choice of grammar subjects and the way in which subjects are handled. It is particularly notable that the set effectively uses the helical learning approach. The set's adoption of a communicative method is also reflected in the workings of grammatical subjects, and provides current examples to keep words in mind. It should be expected that all levels of the set will be finished in order to understand some issues, since the full end and understanding of the subjects will be possible by the end of all stages of the set. Because in the preparation of the set, the method of induction, which means reasoning in the form of transition from private to public or from events to laws, was adopted. In our opinion, if the grammatical subjects of this set are handled well in the classroom environment, there will be no need to read another grammar book.
\end{abstract}

\section{STRUCTURED ABSTRACT}

This study focuses on the grammar subjects and the method of processing the grammar subjects of al-Yâsemîn which consists of two books, one of which is a book of students, published in United Arab Emirates / Dubai in 2017. Set has been started to be taught in the preparatory class of the Department of Arabic Translation and Interpretation, Faculty of Humanities and Social Sciences, Yıldırım Beyazit University, Ankara only in the academic year of 2018-2019. The aim of the study is to give the teachers and students an idea about this by presenting the method of teaching the grammar in the mentioned set. The review is limited to the two existing books of the set. Qualitative research method was used and data were collected and analyzed.

The set consists of fifteen units. There are five courses in each unit and each one of the five courses shows a level. The first five lessons of the set were prepared according to A1, the second five lessons A2 and the third five courses according to the B1 level. Levels and conformity are shown on the outer cover of both books. The set is geared towards teaching four language skills and offers many activities, including language games, to acquire these skills. At the end of each of the five 
units, there are four exam sections prepared according to the skills. Set also offers many extracurricular possibilities in virtual environment. These include language games, videos and course materials. The teacher's book and other activities of the set can also be accessed at alyasameen.net.

After examining the set in terms of the grammar teaching method and the method of processing the subjects, there were two results:

\section{1-Positive Aspects of Set in terms of Grammar Teaching}

-The textures are explained from simple to difficult, simple to complex by inductive method.

Spiral learning approach method has been adopted and applied.

-Privately about the verb conjugation of the past, the ban and some forms of orders of elephants are not given all the forms were given.

-The language is used in a clear and comprehensible language.

- Explanation has been made sufficiently for the subjects.

- Mold expressions that the student will use in daily life are included.

The subjects of the discipline are given in four skill exercises. separately.

-The differences between the other topics are discussed

-The order of the subjects except for one subject is correct.

-To give you a piece of information on the subject just before the subject of knowledge.

\section{2-Negative Aspects of Set for Grammar Teaching} units

- Comprehensive and varied processing of knowledge in some

-The processing of some issues (such as delicacy) is delayed and the places are not suitable

- Examples of issues that students had never heard about in several subjects were given. It's like using nekira in the news.

As a result, the Arabic education set al-Yâsemînı was considered to be successful as a method of handling grammar subjects and subjects, except for a few subjects. It is noteworthy that the set uses the spiral learning approach effectively. The adoption of a communicative method by the set reflects the grammatical issues in their works and reinforces this by giving current examples. It is to be expected that all of the set's levels will be finished in order to grasp some issues as the subjects will be finished and understood by the completion of all stages of the set. Because in the preparation of the set, from the special to the general or the transition from law to the law, to adopt the method of induction is adopted.

\section{Suggestions}

Although the al-Yâsemîn set is generally grammatically successful, the fact that some units are intensively worked is a problem 
for the student. In this respect, I believe that it would be more beneficial to shift some of the issues in the last units of the B1 level to B2 if it is necessary to distribute these dense parts to other issues. On the other hand, I would like to re-review the order of some subjects and make a change of place. In fact, the conditions of Turkey and Turkish students before and this is the biggest lack of Arabic grammar is explained in sets like this. Therefore, I believe that it is necessary to prepare the sets that will eliminate this deficiency.

It should be expected that all levels of the set will be finished in order to understand some issues, since the full end and understanding of the subjects will be possible by the end of all stages of the set. Because in the preparation of the set, the method of induction, which means reasoning in the form of transition from private to public or from events to laws, was adopted. In our opinion, if the grammatical subjects of this set are handled well in the classroom environment, there will be no need to read another grammar book.

Keywords: “el-Yâsemîn" Education Set, GrammarEducation, Method, BookReview, Book Evaluation.

\section{Giriş}

İslam'ın doğduğu yıllarda kabile dili olan Arapça, İslam'ın yayıllışıyla birlikte Doğu'da ve Batı'da çok geniş bir alana yayılmıştır. Müslüman olan milletlerden Arap yarımadasına gelip yerleşenler olduğu gibi fethedilen ülkelere giden Arap halkın oralardaki yerli halkla kaynaşması neticesinde Arapça öğrenmeye ilgi artmıştır. Ancak bu artış, Arapçanın öğretim veya öğrenim özelliğinden çok Arapçayı toplumların ana dillerinin yerine geçirme şeklinde olmuştur. Böylece bu topluluklar, kendi toplumlarında veya Arap toplumları içinde kuralsız ve bozuk bir Arapça lehçesinin ortaya çıkmasına sebep olmuşlardır (Doğan, 1989: 32). Ortaya çıkan bu durumdan Türkler de nasibini almiştır.

Uzun bir geçmişe dayanan ilişkiler sonucu Arapçanın Türkçeyi etkilediği bilinmektedir. Arapçanın Türkçeye etkisi kadar olmasa da Türkçe de Arapçaya etkide bulunmuştur. Türklerin İslamiyet ile tanışmasından önce başlayan bu alışveriş, İslamiyet sonrasında da devam etmiştir. İslam fetihlerinden sonra Türkler halife ordularında önemli mevkilere gelmişlerdir. Karahanlılar, Gazneliler, Tolunoğulları, Büyük Selçuklular, Anadolu Selçukluları'ndan Osmanlılara gelinceye kadar ki Türk devletleri zamanında, Araplarla Türklerin iç içe yaşamaları sonucu hiç şüphesiz Türkçe Arapçayı etkilemiş ve bu dile pek çok kelime vermiştir (Kaymaz, 2011: 70).

Dilbilgisine Arapçada, nahiv veya kavâid adı verilir. Terimsel olarak "Arapça terkiplerdeki kuralları inceleyen ilim dalı", "cümleleri sağlamlık-bozukluk yönünden inceleyen ilim dalı" (elCürcani, ty: 240), "Nahiv, Arap sözlerinin anlam ve şekilleri arasındaki ilişkiyi anlayabilmek ve bu yolla anlam ve şekillerini birbirine yaklaştırmak amacıyla, onların kullandıkları bakış açısından bakarak inceleyen bir ilimdir.”(el-Fergani, 1986: 3) şeklinde değişik tarifleri yapılmıştır.

Arapça dilbilgisi kuralları oldukça fazladır ve öğrenmesi de eğer iyi bir yöntem uygulanmazsa zordur. Ancak Arapça kuralları bu kadar zor hale getiren sadece kuralların çokluğu ve karmaşıklığı değildir. Yüzyıllardır bilginlerin kurallar üzerinde gereksiz açıklama ve yorumları konuları iyice içinden çıkılmaz bir hale getirmiştir. Bu yüzden zaman zaman Arapça kuralları kısaltmak ve kolaylaştırmak için bilginler tarafından girişimlerde bulunulmuş ancak her defasında klasik yönteme dönmek zorunda kalınmıştır (Altun, 2017: 52). Kanaatimizce bunun sebebi, bu konuda bütün Arap ülkelerinin aynı görüşü paylaşmaması olabileceği gibi gelenekçilikten kurtulamama psikolojisi de olabilir. 
Arap gramerinin kurallarının baskın olduğu dönemlerde artık iş çı̆̆ırından çıkmış, gramer kuralları demirden bir duvar gibi şair ve yazarların önünü kesmiştir. Bu husus Arap şiirinde de kendini göstermiştir. Dilbilgisini şiir yoluyla öğrenmenin daha faydalı ve iyi olduğunu, kuralların eğlenirken öğrenildiğini öne sürenler olduğu gibi (Dağbaşı, 2018: 392), nahivcilerin her gördükleri şiirde irap aradıklarını ve bu durumun kendilerini sıkıntıya soktuğunu söyleyen şairler de olmuştur. Daha önce söylediği bir şiirde hata yaptığı belirtilen şair Amr el-Kelbî, kendisinin de bir Arap olduğunu söyleyerek sıkıntısını,

\section{-Irabcılardan ve icat ettikleri şu nahivlerinin kıyasından çektiğimiz nedir?}

-Kıyas veya ölçü olarak ortaya koydukları şeyin aksine yeni bir beyit söylersen,

- "Yanlış yaptın, bu mansub değil, bu mecrurdur, bu da merfu değildir" derler,

-Benim her sözüm size açık olacak değildir. Anladığınızı alın anlamadı̆̆ınızı bırakın.

şeklinde dile getirmiştir (Bakırcı-Demirayak, 2001: 170).

Arapça fasih dilin bozulması endişesiyle dilin kurallarının tespit edilmesi olayı, bir bakıma Arapçanın yabancı dil olarak doğru öğretimi olarak nitelenebilir. Zaman içinde o kadar çok kural ortaya konuldu ve o kadar çok açıklama yapıldı ki artık Arap grameri anlaşılmaz bir kurallar yumağ halini almıştır. Nahiv ilminin gelişmesi döneminde gereksiz kurallara boğulduğunu gören Halefu'lAhmer ( 180/796), nahiv usulünün anlaşılması için "Mukadimmefi'n-Nahv" adlı kitabını yazmıştır. Yapılan uzun açıklama ve yorumlara Arapça öğrenenin hiç ihtiyacı olmadığını belirten Ebu'l-Ala elMa'arrî (449/1057) yorumun zorluk ve anlamdan uzaklaşma olduğunu savunmuştur. Bir çoknahivci, nahvin kolaylaştırılmasıyla ilgili çalışmalar yaptılarsa da her seferinde geriye dönülmek zorunda kalınmıştır.

19.yy.'da nahiv öğretimine çözüm getirebilmek için yeni dilbilgisi kitapları yazılmaya başlanmıştır. Pek çok kimse tarafından benimsenen Arapçayı kolaylaştırma çalışmalarının lideri; Mustafa Ğalâyînî'dir. Bu maksatla o, "Câmi'u'd-Durûsi'l-Arabiyye" adlı eserini yazmıştır. Arap gramerini kolaylaştırma adına yazılan bir başka eser de Reşîd eş-Şartûnî'nin "Mebâdi'u'l-Arabiyye" isimli kitabıdır. Konu, alıştırma ve örneklerin öğrenci hayatı ve çevresiyle bağlantılı olmasına özen gösterilen bu kitapta, diyalog metodu kullanılmıştır (Doğan, 1989: 40). Mustafa Ğalâyînî 'Câmi'u'dDurûsi'l-Arabiyye" adlı eserinin mukaddimesinde "Arapça öğretimindeki zorlukları görünce çok acil olarak aşamalı olarak konuları basit ve anlaşılacak şekilde işleyen kitaplar yazmak zorunda kaldım." demektedir (Ğalâyînî, 1966: 4).

Nahiv çalışmalarına kapsamlı, sistematik ve bir bütün olarak karşı çıkan ve nahvin kolaylaştırılmasını isteyen ve bu konuda ilerideki tartışmalara zemin hazırlayan kişi Endülüslü ünlü nahivciİbnMada (ö. 592/1195) olmuştur. İbnMada, nahivde illet, kıyas, bedel, amil-mamul, takdir teorilerinin bırakılmasını ve nahiv kurallarının ilgasını istemiştir. Amil ile mamul arasında herhangi bir ilişkinin olmadığını ileri sürmüş ve bu konuların Arap dilini donuklaştırdığını iddia etmiştir. Nahivcilerin koyduğu kuralların faydasız ve birer varsayımdan ibaret olduğunu, bundan dolayı da nahivcilerin dil öğretimini zorlaştırdığını 1srarla belirtmiş ve bu konuyla ilgili olarak meşhur "erReddala'n-Nuhât" isimli kitabını kaleme almıştır (Bakırcı-Demirayak, 2001:162).

Dilin temelini oluşturan dilbilgisi öğretiminin asıl amacı, insanın bilinçaltında doğuştan var olan dilbilgisi yapısı ve kurallarını bilinç seviyesine çıkarmak ve bunların bilinçli bir şekilde kullanmalarını sağlamaktır. Bu yüzden dil eğitimindeki yeni yaklaşımlara göre dilbilgisi öğretimi, kural ezberletmek veya teorik bilgi vermek değil, esas amaç sözlü ve yazılı iletişimde bir takım yanlış ve aksaklıkları gidermek için dilbilgisini bir araç olarak kullanmaktır (Dolunay, 2010: 277).

Arapça dil ögretiminde dilbilgisinin yeri ve önemi konusunda tartışmalar ve çalışmalar süregelmiştir. Bu çalışmaların neticesinde, dilbilgisi öğretimi konusunda yeni yaklaşım ve yöntemler 
ortaya çıkmıştır. Gramersiz olmaz diyenler kadar dilbilgisini gereksiz görenler de vardır. Dilbilgisini gerekli görenlerin görüşlerini şöyle özetlemek mümkündür: Dilbilgisi kurallarıyla ilgili derin bir bilgisi olmayan kişiler yabancı dilde uzmanlaşamazlar. Sağlam bir dilbilgisine sahip olanlar, yabanc1 dili üretici olarak kullanabilirler. Hedef dilde iyi bir dilbilgisi birikimine sahip olan öğrenciler, güçlü iletişim becerilerine sahip olurlar. Bu görüşü savunanlar, günümüzde dilbilgisinin bireyin dili iyi anlamas1, iletişim kurması, zihinsel becerilerini geliştirmesi amacıyla öğretildiğini, dil bilgisinin sadece bir iletişim aracı değil aynı zamanda dili tanıma ve öğrenmenin konusu olduğunu söylemektedirler. Gramer öğretimini gereksiz görenler ise, grameri tamamen devre dişı birakmamakla beraber, dilin gramerle öğrenilemeyeceğini, dilbilgisinin bir zaman kaybı olduğunu, bilinçli gramer eğitiminin bilinçaltı dil edinim becerisini zayıflattığını ve iletişimi yavaşlattı̆̆ını ileri sürmektedirler (Altun, 2017: 35-38). Öte yandan üçüncü bir grup da orta yolu tutarak gerektiği kadar ve belirli yöntemlerle dilbilgisi öğretimini savunmaktadırlar. Kanaatimizce de gerektiği kadar ve iletişimsel bir yöntemle gramer öğretinin yapılması bir dilin öğrenilmesinde zaruridir. Çünkü dili doğru konuşmak ve yazmak, dilbilgisi kurallarının bilinmesiyle mümkün olmaktadır.

Yılmaz'a göre (2018: 4), dilbilgisi öğretimi birçok yapının öğrenciye kazandırılması konusunda zaman kazandırmaktadır. Bir anlamda daha kısa zamanda daha iyi kazanımlar elde etmek demektir. Bu sayede öğrencilere karmaşık gelen yapılar öğrencinin zihninde daha iyi pekişmektedir. Dil öğretiminin amaçlarından biri de hedef dilden anadile tercüme yapabilmektir. Hedef dilde söylenen ya da yazılan bir cümleyi dilbilgisel olarak doğru anlayan kişi ana dile düzgün çeviri yapacaktır. Bu anlamda dilbilgisi eğitimi büyük önem taşımaktadır.

Yabancı dilde gramer öğretiminin nasıl olması gerektiği konusunda el-Hûlî (2000: 43), cümlenin gramatik anlamının sözcük anlamı kadar önemli olduğunu söylemektedir. Ona göre, okuyucu veya dinleyici herhangi bir cümlenin kelimelerinin anlamlarını anlayabilir. Fakat cümlenin bütünsel anlamını anlayamaz; çünkü cümlenin gramatik anlamını anlamamıştır. Eğer okuyucu veya dinleyici bir cümlenin kelimeleri arasındaki bağlantıları anlamamışsa bu onun anlamı anlamasını engeller. Öğretmenin cümlenin gramatik anlamını kavraması konusunda öğrencilere yardımcı olması gerekir. Öğretmen, cümle içindeki kelimelerin bağlantılarını, fonksiyonel kelimelerin anlamda üstlendikleri rolleri, tonlamanın anlama nasıl etki ettiğini, morfolojik biçimlerin anlamlarının önemini açıklamalıdır.

Hasan Şahate göre (1992: 204), gramer konuları okuma ve yazma parçalarının içinde işlenmeli ayrı bir ders olarak işlenmemelidir. Gramerin dilin bizzat kendisinden öğrenilmesi gerektiğini savunan Şahate, okuma ve yazma derslerinde öğrencilerin yapacakları hatalardan yola çıkarak onlara dilbilgisi kurallarının anlatılmasının daha etkili olacağını, kuralları anlatmak yerine uygulama yapılması gerektiğini belirtmektedir. Gramer dersini ayrıca bir ders olarak okutmanın dili öğretemeyeceğini, tam tersine öğrencinin dilin esasını anlamasını engelleyen bir unsur olarak gören Şahate, okuma parçaları içinde öğretilecek kuralların da öğrencinin seviyesine uygun olmasının şart olduğunu söylemektedir.

Bir yabancı dil olarak Arapça öğretimin başarılı olması için Türkçe ile karşılaştırmalı Arapça öğretim metot ve tekniklerinin bilimsel olarak araştırılıp, yeni yöntemlerin geliştirilmesi gerekir. Arapçayı öğretecek öğretmenlerin çağdaş uygulamalı dil bilimin gereklerine göre yetiştirilmelidirler. Arapça öğrenenlerin ihtiyaçlarının bilimsel yöntemlerle belirlenmesi gerekir. Amacın belirlenmesi öğretimi öğrenci merkezli yapar ve bu da öğretimi kolay ve özendirici hale getirir. Bunun için belirlenen amaçlara uygun programlar hazırlanmalıdır (Doğan, 1989: 58).

Kanaatimizce de Arapça gramer öğretiminin başarılı olabilmesi için öncelikle gramerin amaç değil araç olması gerektiği gerçeğini hem öğrenenler hem de öğretenler kabullenmelidir. Gramer ögretiminde amacın iyi belirlenmesi, konuların tespiti ve iyi bir şekilde sıralanması, özel örneklerin seçiminin yapılması ve bilimsel teknik ve yöntemlerin titizlikle belirlenmesi, gramer öğretimini daha kolay ve daha zevkli bir hale getireceği muhakkaktır. 
Bu çalışmanın amacı, adı geçen setteki dilbilgisi öğretim yöntemini ortaya koymak suretiyle bundan sonra bu seti okutacak ve okuyacak öğretmenlere ve öğrencilere bu konuda bir fikir vermektir. İnceleme, setin mevcut iki kitabıyla sınırlandırılmıştır. Çalışmada nitel araştırma yöntemi kullanılmış, elde edilen veriler toplanarak analize edilmiştir.

\section{Problem}

Neredeyse her yıl Arapça eğitimi ve öğretimi alanında yurt içi ve yurt dışında farklı öğretim setleri piyasaya sürülmektedir. Bu durum, Arapça öğrencileri ve eğitimcileri açısından oldukça memnuniyet vericidir. Ancak bu setlerin bir kısmının ticari amaçlı olduğu bir kısmının da Türklerin öğrenme mantığına uymadığını da ifade etmek de fayda olduğu düşüncesindeyim. Son olarak 2017 yılında piyasaya çıkan ve Birleşik Arap Emirlikleri/Dubai'de hazırlanan "el-Yâsemîn" isimli set, ülkemizde okutulmaya başlanmıştır. Set halihazırda sadece Ankara Yıldırım Beyazıt Üniversitesi, İnsan ve Toplum Bilimleri Fakültesi, Arapça Mütercim-Tercümanlık Anabilim Dalı hazırlık sınıfında 2018-2019 eğitim-öğretim yılında okutulmaktadır. Setin yöntem ve biçimsel analiziyle ilgili sonuçları başka bir makalemizde dile getirmiştik. Bu makalede ise setin farklı bir yöntem olarak gördüğümüz dilbilgisi konuları ve bunları işleme yöntemini ele alacağı. Çalışma, setin dilbilgisi eğitimi ve konularının ülkemizdeki Arapça öğrenenlere uygun olup olmadığını, varsa eksiklerinin neler olduğunu ve öğrencilere ne kadar yararlı olabileceği konularını bir problem olarak görmüştür.

\section{2. Önem}

Dil öğretiminde artık yeni bir dönem girilmiş ve neyin öğretileceğinden çok nasıl öğretileceği konusu ön plana çıkmıştır. Dolayısıyla yazılan kitapların uyguladıkları yöntemler önem kazanmıştır. Bu açıdan okutulacak kitapların çok iyi bir şekilde yetkili ve ilgililerce incelenmesi ve gerekli uyarı ve tavsiyelerin yapılması bilimsel bir görev haline gelmiştir. Buradan hareketle ülkemize henüz yeni gelmiş olan "el-Yâsemîn" Arapça öğretim setinin Türk öğrencilerin alfabeden sonra en çok zorlandıkları konu olan dilbilgisi açısından ele alınmasının faydalı olacağı kanaatindeyiz. Set hakkında daha önce akademik anlamda herhangi bir çalışma bulunmamaktadır. Ancak, bu çalışmamıza benzer başka bir çalışma vardır. Bu çalışmada, yine ülkemizde 3-4 yıldan beri okutulan "Silsiletu'l-Lisan" isimli setin, öğrenci-öğretmen görüşlerine göre yöntemsel açıdan değerlendirilmesi yapılmıştır (Özcan, vd., 2016).

\section{Amaç}

Çalışmanın amacı, ülkemizde yeni okutulmaya başlayan "el-Yâsemîn" isimli Arapça eğitim setinin dilbilgisi eğitimi açısından yeterli olup olmadığını belirleyerek, yeterli olan taraflarını ortaya koymak, yetersiz tarafları varsa bu konuda yapılması gerekenler konusunda önerilerde bulunmak ve Arapça eğitim veren kurum ve ilgilileri bu konuda bilgilendirmektir.

\section{Sinırlılıklar}

Çalışma iki kitaptan oluşan "el-Yâsemîn” isimli Arapça eğitim seti ile sınırlı tutulmuştur.

\section{Yöntem}

$\mathrm{Bu}$ bölümde araştırmanın modeli, evren ve örneklemi, verilerin toplanması ve analizi bilgilerine yer verilmektedir.

\subsection{Araştırmanın Modeli}

"el-Yâsemîn" isimli Arapça eğitim setinin Arapça dilbilgisi öğretim metodu açısından değerlendirilmesini ele alan bu araştırmada tarama modeli kullanılmıştır. Tarama modeli, geçmişte olmuş ya da halen var olan durumu, var olduğu haliyle betimlemeyi amaçlayan araştırma yaklaşımıdır (Karasar, 1999: 77). 


\subsection{Evren ve Örneklem}

Araştırmanın evrenini, Arapça eğitimine yönelik yazılmış tüm kitaplar ve eğitim setleri, araştırmanın örneklemini ise, "el-Yâsemîn" isimli eğitim seti oluşturmaktadır.

\subsection{Verilerin Toplanması}

Araştırmada veriler, çalışmaya konu olan setin dilbilgisi konularının tamamı taranarak elde edilmiştir. Verilerin toplanmasında zaman zaman diğer eğitim setleri ve dilbilgisi kitaplarıly setteki konuların anlatılış biçimleri yöntemsel olarak karşılaştırılmıştır.

\subsection{Verilerin Analizi}

Elde edilen verilerin analizinde, konunun yeterince ve açık bir dille verilip verilmediğine, seviyeye uygun olup olmadığına bakılmıştır. Ayrıca konular hakkında gerektiği kadar örneklerin verilip verilmediğine ve örneklerin günlük hayattan olup olmadığı kontrol edilmiştir. Bunun yanında dilbilgisi konularıyla okuma parçalarının paralelliği gözlemlenmiştir. Daha sonra teorik bilgilerin veriliş şekilleri ve örneklerin incelenmesine geçilmiştir. Elde edilen veriler gruplanmış ve aynı konuda olan veriler bir başlık altında toplanmıştır.

\section{Bulgular ve Değerlendirme}

$\mathrm{Bu}$ bölümde elde edilen verilerin analizine yer verilmiştir. Bulguların analizi aşağıdaki inceleme sırasına göre yapılmış:

1- Set hakkında genel bilgi

2-Setteki dilbilgisi konularının tasnifi

3-Dilbilgisi konularının işlenişi ve öğretim metodu yönünden incelenmesi

\subsection{Set Hakkında Genel Bilgi} verilmiştir.

“el-Yâsemîn” Arapça öğretim seti iki kitaptan oluşmaktadır. Aşağıda setin künyesi

Kitabın Adı : el-Yâsemîn

Alt Başlı̆̆1 : Silsile fî Ta'lîmi'l-Luğati'l-Arabiyyelin-Nâtıkînebi-Ğayrihâ

Yazarı : MuhammadBahgatKanafani

Yayın Y1l1 : 1. Bask1, 25 Mart 2017

Yayınevi : AlYasameen Yayınları-Dubai, UAE

Ünite Say1s1 : XV

Sayfa Say1s1 : 240

Cilt : Karton kapak, kuşe kâğıda bası11, $21 X 28 \mathrm{~cm}$. ebadında

Düzey : A1, A2, B1

Set on beş üniteden oluşmaktadır. Her düzeyde beş ders bulunmaktadır. Setin ilk beş dersi A1, ikinci beş dersi A2 ve üçüncü beş dersi de B1 düzeyinde ve Avrupa Ortak Başvuru Metni'ne göre hazırlanmıştır. Her iki kitabın dış kapağında düzeyler A1, A2 ve B1 şeklinde gösterilmiştir. Set, dört dil becerisini öğretmeye yönelik hazırlanmış olup, bu becerilerin kazanılması için dil oyunları da dâhil pek çok aktivite verilmektedir. Her beş ünite sonunda dört beceriye göre hazırlanmış sınavlar bölümü yer almaktadır. Set ayrıca sanal ortamda ders dışı pek çok imkân sunmaktadır. Bunlar arasında dil oyunları, videolar ve ders materyalleri sayılabilir. Setin öğretmen kitabına ve diğer aktivitelere yine alyasameen.net adresinden ulaşılabilmektedir. 
Setin alıştırma kitabı, setteki konularla ve düzeylerle paralel gitmektedir. Ayrıca alıştırma kitabında ana kitapta olmayan ve öğretilen dilbilgisi ve diğer konularla ilgili farklı alıştırmalar bulunmaktadır. Set esasen alıştırma kitabıyla bir bütünlük kazanmakta olup, öğrencinin ana kitapta öğrendiği kural, kelime ve kalıplar alıştırma kitabında tekrar ele alınmakta ve bu kalıp ve kelimelerle yeni cümleler kurulmaktadır. Dolayısıyla öğrencilerin alıştırma kitabını çalışmadan setten tam anlamıyla istifade etmeleri zor görünmektedir. Kanaatimizce alıştırma kitabındaki konular ödev olarak verildikten sonra, sınıf ortamında bu konuların üzerinden bir kez daha geçilmesi daha yararlı olacaktır.

\subsection{Setteki Dilbilgisi Konularının Tasnifi}

“el-Yâsemîn” isimli Arapça öğretim setinin dilbilgisi bölümleri için,

قَاعَدَة ikonun kullanıldığını ve bu işaretin altında dilbilgisel bir özetin bulunduğunu görüyoruz. Ayrıca فَائدَة ikonu altında, dilsel ve kültürel bazı önemli bilgilerin bulunduğu içerikten anlaşılmaktadır. Dilbilgisi bölümünde çoğu zaman konu birkaç cümleyle açıklanmış ve örnekler verilmiş̧ir. Dilbilgisi konularının özet olarak verildiği ana kitaptan sonra asıl pekiştirmenin ve kavranmanın alıştırma kitabındaki aktivitelerle sağlandığını söylemeliyiz. Dolayısıyla alıştırma kitabı okunmadan hem setteki diğer konular hem de dilbilgisi konuları tam anlamıyla kavranamayacaktır. Aşağıda setin ana kitabı olan “Öğrenci Kitabı”"ndaki dilbilgisi konularının ayrıntılı bir dökümü yapılmıştır.

\begin{tabular}{|c|c|}
\hline & A1 Düzeyi \\
\hline 1. Ders & Harflerin yazımı ve noktalar \\
\hline 2. Ders & 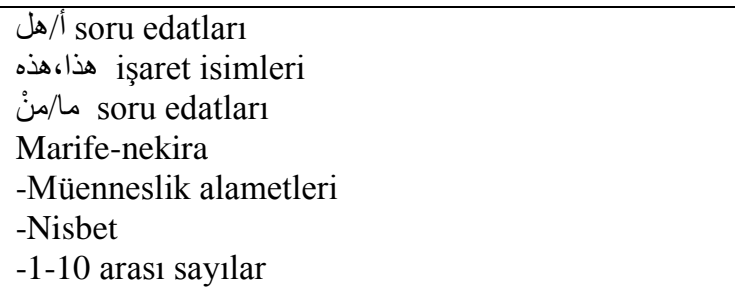 \\
\hline 3. Ders & $\begin{array}{l}\text {-Lâmu'ş-şemsiyyeve'l-kameriyye } \\
\text {-İsim ve sifatlarda olumsuzluk } \\
\text {-Muzari fiil. Ben,sen,sen(Müe.), biz } \\
\text {-_..................................kalıp ifadesi } \\
\text {-İkiller hariç ayrı zamirler } \\
\text {-Sifat -mevsuf (uyum) } \\
\text {-11-20 arası sayllar }\end{array}$ \\
\hline 4. Ders & $\begin{array}{l}\text {-Muzarifiil : Siz (müz), o (müe/müz.), onlar (müz.) } \\
\text {-Fail } \\
\text { - ألن/ألن// Soru edatları }\end{array}$ \\
\hline 5. Ders & 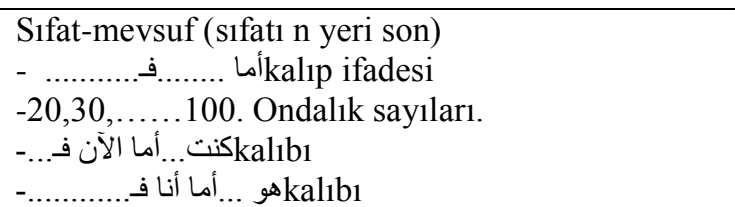 \\
\hline & A2Düzeyi \\
\hline 6. Ders & 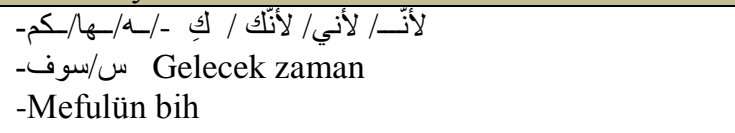 \\
\hline 7. Ders & $\begin{array}{l}\text {-Sıra say1ları (1-12) } \\
\text {-Mazi fiil : ben,biz siz (müz) ve o/o, onlar } \\
\text { - لقذ/قد - لقد }\end{array}$ \\
\hline
\end{tabular}

Turkish Studies - Language and Literature

Volume 14 Issue 2, 2019 


\begin{tabular}{|c|c|}
\hline 8. Ders & $\begin{array}{l}\text {-Mazi ve muzari fiilde olumsuzluk } \\
\text { - عند/ لدان- ve gurubunun isim ve fiil cümlesiyle kullanımı } \\
\text { - كان ve }\end{array}$ \\
\hline 9. Ders & 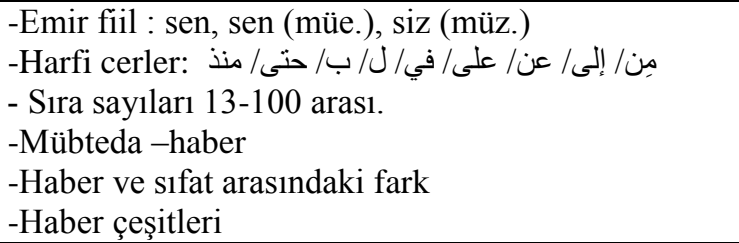 \\
\hline 10. Ders & 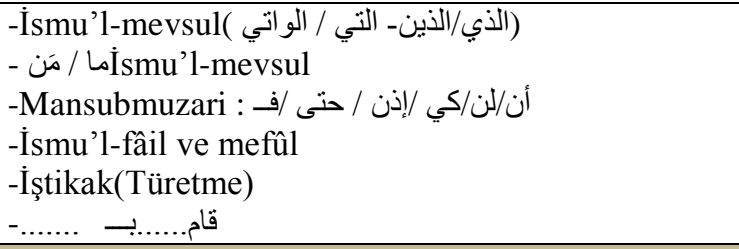 \\
\hline & B1 Düzeyi \\
\hline 11. Ders & $\begin{array}{l}\text {-İsmu’t-tafdîl } \\
\text {-Teaccübuslubu } \\
\text {-200-1000 sayıları } \\
\text {-1-99 sayıları arasındaki aded-madud ilişkisi } \\
\text {-Cemi müzekker salim ve irabı } \\
\text {-Cemi teksir } \\
\text {-İsmumaksur, memdud, meksur } \\
\text {-Cemi müennes salim ve irabı } \\
\text {-Hemzenin yazılışı }\end{array}$ \\
\hline 12. Ders & $\begin{array}{l}\text { - كان ve grubunun irab1 } \\
\text {-Hemze-i vasl ve kati } \\
\text { إنّ ve grubu ve irab1 } \\
\text { إنّ ve grubuna ي zamirinin birleşmesi. }\end{array}$ \\
\hline 13. Ders & 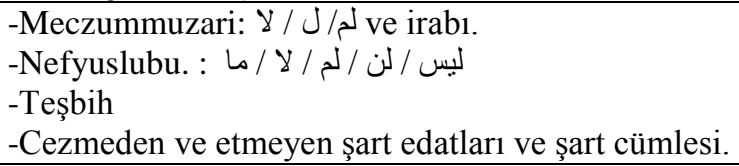 \\
\hline 14. Ders & $\begin{array}{l}\text {-Tesniye ve irabı } \\
\text {-İstisna } \\
\text {-sahih ve mutel fiiller } \\
\text {-Gereklilik kipi }\end{array}$ \\
\hline 15. Ders & $\begin{array}{l}\text {-Meçhul fiil: mazi, muzari } \\
\text {-Naibu'l-fail }\end{array}$ \\
\hline
\end{tabular}

\subsection{Dilbilgisi Konularının İşlenişi ve Öğretim Metodu Yönünden İncelenmesi}

Dilbilgisi öğretiminin açıkça ya da örtük olarak yapılmasının gerekli olup olmadığının tartışıldığı çeşitli dil öğretim yöntem ve ilkeleri bulunmaktadır. Dil öğretim uzmanları, dil öğrenenlerin biçimden ziyade anlama önem vermeleri gerektiği ve anlam çerçevesinde dili kullanmayı öğrenmeleri gerektiğini tartışmaya devam etmektedirler (Yılmaz, 2018: 4).

Dilbilgisi insanın öğrenmeyi amaçladığı yabancı dili doğru anlama ve anlatmasına yardımcı olur. Dolayısıyla dil öğretilirken, o dilin kurallarını doğru, saf ve duru bir şekilde öğretmek ve kullanımı kolay, günlük hayatta kullanılabilecek yapıların öğretimine daha fazla önem vermek gerekmektedir. Son yıllarda Arapça dilbilgisini örtük olarak öğretme yolu izlenmeye başlamıştır. Modern metot da denilen bu yöntemde kurallar, teorik bilgiden önce pratik olarak öğrencinin önüne konulmaktadır. Daha sonra da gayet arı ve anlaşılır bir şekilde kurallar verilerek değişik aktivitelerle kavratılmaya çalışılmaktadır. İncelediğimiz bu sette de bu yöntem benimsenmiş ve konular gayet kısa 
ve öz anlatılmıştır. Biz bu setin dilbilgisi konularını incelerken aşağıdaki esasları göz önünde bulundurduk:

1-Konunun işleniş zamanlaması, konunun işleniş sırası

2-Konunun anlaşı1ır bir şekilde anlatılıp anlatılmadığı

3-Konunun yeterince anlatılıp anlatılmadığı

4-İşlenen konunun anlaşılması için yeterli alıştırmanın verilip verilmediği

5-İşlenen dilbilgisi kuralının diğer dil etkinliklerinde yeterince işlenip işlenmediği.

Setteki dilbilgisi konularının akışına bakıldığında, Türkiye'deki müfredata uygun hazırlanan dilbilgisi kitaplarıyla (Günday- Şahin, 2005: Sarmış, 2005) paralellik göstermediği görülmektedir. Örneğin; Türkiye'deki klasik dilbilgisi kitaplarında ilk konu "cümle çeşitleri”" iken, fiil cümlesi setin dördüncü dersinde, isim cümlesi ise yedinci dersinde yani A2 düzeyinde ele alınmıştır. Bu iki cümle çeşidine gelene kadar cümleyi oluşturan fiil, tamlamalar ve zamir gibi isimsel unsurlar yani cümlenin parçaları anlatılmış daha sonra bir kelimeler topluluğu olan cümleye geçilmiştir. Set, kısmen bizim de doğru bir yaklaşım olarak gördügümüz ve özelden genele ya da olaylardan yasalara geçiş şeklindeki akıl yürütmek anlamına gelen tümevarım (Akarsu, 2007: 47) yöntemiyle konuları işlemiştir. Ayrıca set iletişimsel öğrenme kuramını takip etmiş ve öğrenci-öğretmen çalışmasına olanak tanımıştır.

Setin eldeki mevcut kitabı daha önce belirtildiği gibi A1, A2 ve B1 düzeyleri için yazılmıştır. $\mathrm{Bu}$ düzeydeki dilbilgisi konularının çoğunun ilk basamağı ya da en fazla ikinci basamağ1 diyebileceğimiz bilgiler verilmiştir. Demek ki daha sonra çıkacak olan B2, C1 ve C2 düzeylerinde bu konular tamamlanacaktır. Buradan da yine setin tümevarım yöntemiyle yazıldığı sonucuna varabiliriz. Özellikle fiil çekimlerinde kitabın oldukça temkinli davrandığı ve şahıs çekimlerini yavaş yavaş öğreterek sindirilmesini sağladığı görülmektedir. "Câmi'u'd-Durûsi'l-Arabiyye ve el-Arabiyyetu'lFusha/Kur'an Arapçası" gibi klasik yönteme göre yazılmış dilbilgisi kitaplarındaki mazi fille başlama geleneğine aykırı olarak set, muzari fiille fiil öğretimine başlamaktadır. Örneğin; A1 düzeyinin üçüncü dersinde (s.40)muzari fiilin sadece aşağıdaki formları verilmiştir:

\begin{tabular}{|c|c|c|c|}
\hline أنت Sen (müe.) & أنتَ Sen (müz.) & (Biz) نحن & أنا (Ben) \\
\hline تفعلينَ & تفعلُ ت ت ت & 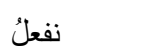 & 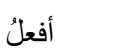 \\
\hline
\end{tabular}

Dördüncü derste (s.52) ise, ikinci şahıs çoğul-eril ve üçüncü şahısların tamamı verilmiştir.

\begin{tabular}{|c|c|c|c|}
\hline ه onlar (müz.) & هي (müe.) & (0) هو (0) & أنتم Ben(müz.) \\
\hline تفعلينَ & تفعلُ & نفعلُ & أفعلُ \\
\hline
\end{tabular}

Böylece, 1. 2. ve 3. şahıs çekimleri ikilleri hariç verilmiş olmaktadır. A1 düzeyinde muzari fiilin başka bir formu verilmediği gibi, mazi fiil formlarından hiçbiri bu düzeyde öğretilmemektedir. Oysa klasik sistemde mazi ve muzari fiilin bütün formları ilk etapta, belki okuma yazmadan sonraki ilk derste, tam çekim olarak öğretilmekteydi. Hatta bu fiiller öğretilirken zamirlerle değil sadece fiilin çekimi öğretilirdi. Ancak öğrenci sadece çekimi bilir, bu fiillerin kullanmasını bilemezdi. Modern metot artık farklı bir yaklaşımla öğretim yapmaktadır. Öncelikle insanın içinde yaşadığ zamanı öğrenerek başlaması aslında mantıken de doğru bir yaklaşımdır. Kişi "gittim” demekten önce "gidiyorum" demeye daha çok ihtiyaç duymaktadır. Kanaatimizce de modern metotların doğuşundaki en büyük etkenlerden birisi, belki de en önemlisi, ihtiyaçların öncelikleri ve zaman kaybının en aza indirilmesi isteğidir. Bu sette uygulanan yöntem de bundan başkası değildir. Setin mazi fiil öğretimi, A2 düzeyinde ve yedinci derste (s.101) yukarıda gösterilen muzari fiil formlarında verilmiş ve set boyunca artık mazi fiilin de muzaride olduğu gibi diğer formları verilmemiştir. Şüphesiz bu fiillerin verilmeyen formları diğer düzeylerde tümevarım mantığı çerçevesinde verilecektir. Zamirlerin 
öğretimi, ismu'l-mevsuller, sıfat, sayıların öğretimi gibi konularda da aynı yöntem kullanılmış ve tümevarım metodu ile konular ikmal edilmiştir.

Öte yandan set aynı zamanda öğrenilen bilgilerin unutulmaması için Sarmal Öğrenme Yaklaşımı 'nı kullanmıştır. İlk derslerde, A1 düzeyinde verilen bir kuralı daha sonraki düzeylerde sık sık kullanarak öğrencinin kuralları özümsemesine yardımcı olunmaktadır. Tümevarım yönteminin benimsendiği sette, A2 düzeyinin üçüncü dersinde (s.119) كان ile ilgili çok küçük bir giriş yapılmış burada iki cümleyle كان ile isim cümlesinin geçmiş zamanda kullanımı gösterilmiştir ve böylece öğrenci ilk defa isim cümlesinin bu amili ile tanıştırılmıştır (Tablo-1).

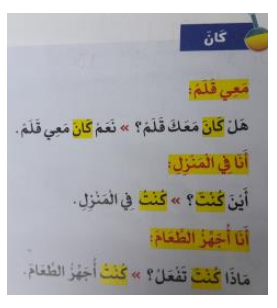

Tablo-1

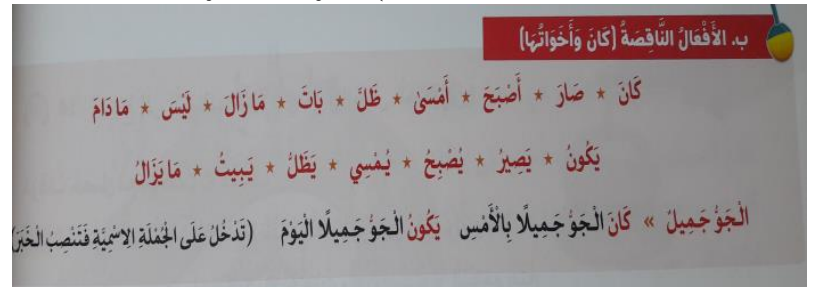

Tablo-2

Fakat ilerleyen ünitelerde B1 düzeyinin dördüncü dersinde (180) كان ve grubu hakkında geniş bilgi verilmiş ve bunların isim cümlesinin başında yaptığı etkisi örneklerle gösterilmiştir (Tablo-2).

Setin bir başka özelliği de, diğer setlerde bir konu olarak rastlamadığımız ve güncel kullanımda gerekli olan bazı yapıları daha ilk derslerde öğretiyor olmasıdır. Örneğin, A1 düzeyinin ikinci dersinde (s.41), ؟.....................mı yoksa.......mı?) kalıbı öğretilmektedir ki bu kalıp ifade

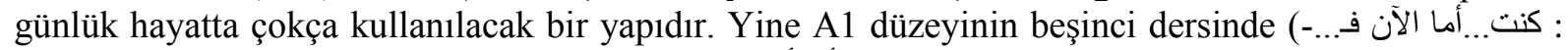
Eskiden şöyleydi şimdi böyle) kalıbı, ve .............أما أنا فو (o şöyle ben ise şöyleyim) kalıpları (s.71) öğretilmektedir. Bizce bu setin diğerlerinden en önemli farklarından birisi, kalıp ifadelere yer vermek suretiyle güncel karmaşık dil yapılarını öğretmesidir.

Setin dilbilgisi konularını işlerken dikkat çeken bir yönü de bazı konularda konuyla ilgili klasik olsun modern olsun günlük hayatta kullanılabilecek kuralları aynı anda vermiş olmasıdır ki bu, öğrencinin kendisini ifade etmekte oldukça geniş bir imkâna sahip olmasını sağlamaktadır. B1 düzeyinin ilk ünitesinde (s.165) taaccüb konusu işlenirken hiçbir sette bir arada verilmeyen oldukça önemli bilgiler verilmektedir. $\mathrm{Bu}$ bilgiler sayesinde öğrenci artık taaccüble ilgili bütün cümleleri çok rahat bir şekilde istediği kalıpla kurabilir (Tablo-3). Burada ilk kalıp klasik Arapçada çok kullanılan bir yapıdır. Aynı anlama gelen ve farklı üç yapıyı daha yer verilmektedir ki modern Arapçada bu yapılar oldukça sık yer almaktadır. Verilen bu yapıları diğer setlerde görememekteyiz.

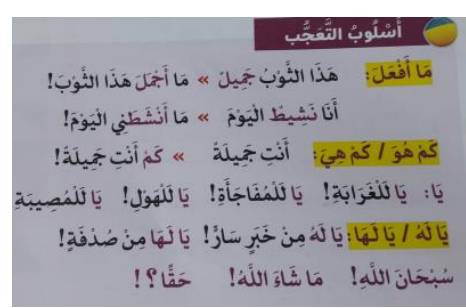

Tablo-3

Yine aynı şekilde B1 düzeyinin dördüncü dersinde (s.206) istisna ile ilgili konuda da aynı yöntem kullanılarak tamamı değil en çok kullanılan istisna yapıları verilmiştir.

Zaman zaman setin bir dilbilgisi anlatımı yapmadan farklı cümle yapılarını verdiği de görülmektedir. Bu durum öğrencinin farklı cümlelerle aynı anlamı elde etmesi açısından oldukça önemlidir. Setin bu ve benzeri yöntemleri kullanması, iletişimsel öğrenmeyi ne kadar öne çıkardığını göstermektedir (Tablo-4, 5).

\footnotetext{
${ }^{1}$ Bruner'in 1960'ta ortaya koyduğu sarmal öğrenme yaklaşımı (SPR) öncelikle ana terimleri belirlemek ve düşük zorluk derecesinden daha zor ve karmaşık problemlere geçmeyi temellendirmektedir. Her yeni düzeye geçişte ilk düzeyde öğrenilen kavramlar kullanılmaya ve tekrarlanmaya devam edilmekte; bu bakımdan öğrenme süreci kesintiye uğramamaktadır. Öğrenciyi merkeze alan bu eğitim biçimiyle öğrencinin içindeki merak duygusu beslenmekte; planlama yapması, araştırmacı olması ve bulgularını paylaşarak, uygulamasını temellendiriyor(http://www.akasyam.com/egitimde-sarmal-yaklasim-nedir?).
} 


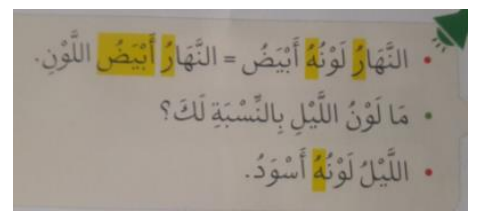

Tablo-4

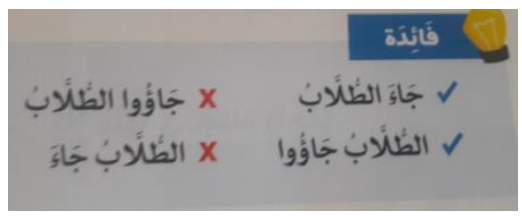

Tablo-5

"el-Yâsemîn" setinin dilbilgisi konularını ele alırken öğrenci için gerekli ve yeterli açıklamaları yaptığı gözlemlenmiştir (s. 164-166)(Tablo 6,7). Ayrıca konu ile ilgili örnekler yeterli olup dilbilgisi konuları dört beceri aktivitelerine yayılmıştır. Aşağıdaki tablolarda gerek adet-madud ilişkisi gerekse ismu't-tafdil ile ilgili açıklamalar bizce tatmin edicidir.

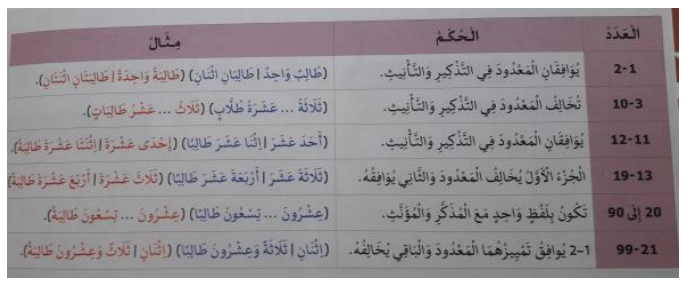

Tablo-6

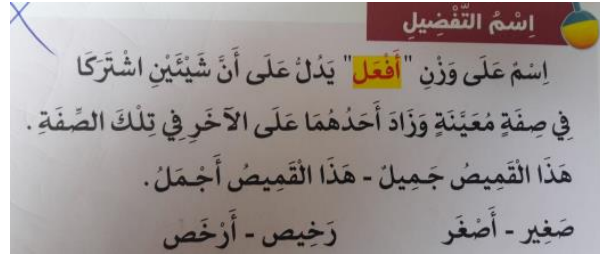

Tablo-7

Aynı konuların ele alındığı Silsiletu'l-Lisan adlı öğretim setinin ilk kitap 108. Sayfasında açıklama bölümü ise şöyledir: (Tablo-8).

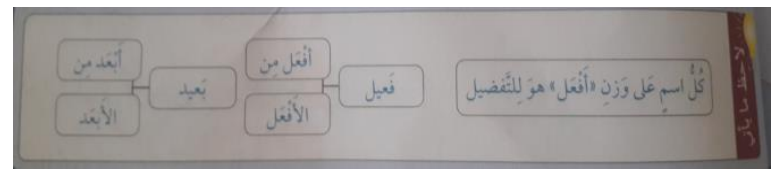

Tablo-8

İncelediğimiz setin bir başka önemli özelliği de, Arapça öğretiminde henüz kendisine hak ettiği yeri bulamayan, karşılaştırmalı yöntemin kullanılmasıdır. Sette bazı benzer konular daha iyi anlașılması için karșılaștırmalı bir metot ${ }^{2}$ ile anlatılmıștır. Özellikle ana dili Arapça olmayanların en çok hata yaptıkları konulardan birisi de birbirine benzer konuları karıștırmalarıdır. Bu bakımdan konuların karşılaştırmalı bir şekilde anlatılması, iyi kavranmaları açısından önemli olduğu kanaatindeyiz. Bununla ilgili setten iki örnek aşağıdaki tablolarda $($ Tablo-9,10) gösterilmiştir:

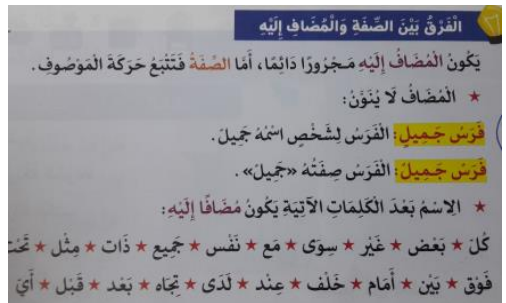

Tablo-9

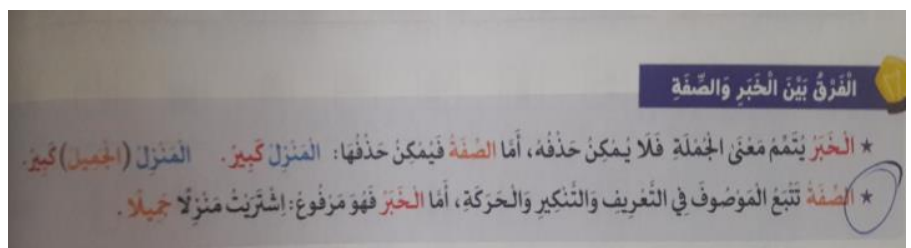

Tablo-10

İncelememiz sırasında setin bazı konuların öğretiminde geç kaldığını da vurgulamamız gerekir. Örneğin, isim tamlaması konusunu, A2 düzeyi üçüncü ünitede (s.118) işlemiştir ki bu

\footnotetext{
${ }^{2}$ Karşılaştırmalı (mukayeseli) metot, belirli olayların ortaya çıkmasında ve gelişmesinde etkili olan fonksiyonel faktörleri sınıflandırmayı ve açıklamayı hedef alan bir araştırma metodunu ifade için kullanılan genel bir terimdir (http://www.bingol.edu.tr/ -arastirma-turleri-ve-karsilastirmali-metot.pdf .
} 
konunun yeri kanaatimizce burası değildir. İzâfet, yani isim tamlaması konusun bizce, A1 düzeyinin sonlarında verilmesi daha doğru olacaktır. Yine sette görebildiğimiz bir husus da öğrencinin bilmediği bazı konularda örnek veriyor olmasıdır ki bu oldukça sakıncalı bir durumdur. Örneğin A2 düzeyinin son konusunda (s.132) haber çeşitlerini anlatırken mübtedayınekira olarak kullanması. Oysa öğrenci o zamana kadar mübtedayı hep marife olarak algılamıştı. Ancak bu durum sette sadece bir yerde

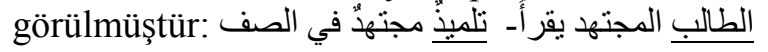

Setin dilbilgisi konularını açık ve anlaşılır bir şekilde anlatmasının, yeterli ve güncel örnekler vermesinin, dört beceri alıştırmalarında dilbilgisi konularını işlemesinin yanı sıra örnekler üzerinde cümle tahlilleri yapması da başka bir özelliğidir (Tablo-11,12).

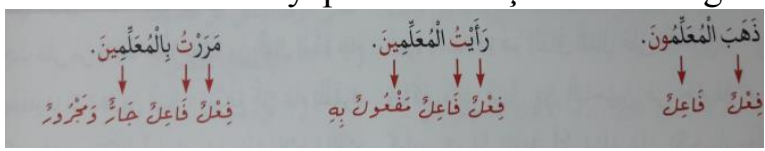

Tablo-11

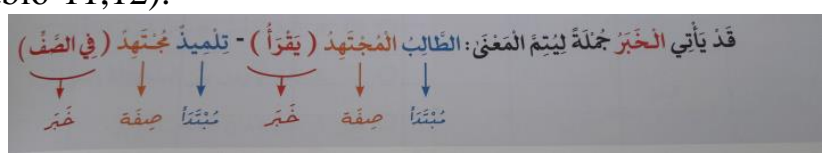

Tablo-12

\section{Sonuç}

Seti dilbilgisi öğretim metodu ve konuları işleme yöntemi açısından inceledikten sonra, bütün setlerde olduğu gibi bu setin de olumlu ve olumsuz yönlerinin olduğu ortaya çıkmıştır. Ancak setin olumlu ve faydalı yanlarının daha çok olduğunu söylemek de fayda vardır. Öğreticilere düşen, "Hatasız kitap olmaz." sözünden hareketle mevcut kitaplar içinde en az hatalı ve eksik olanını tespit ederek öğrencilere sunmaktır. Elimizdeki setin konuları işleme metodunun Türkiye'de yazılan gramer kitaplarından farklı olduğu görülmektedir. Türkiye'deki Arapça gramer kitapları cümleden başlayarak küçük parçalara inmektedir. Yani tümden gelim metodunu uygulamaktadır ki bu sağlıklı bir yöntem değildir. Elimizdeki set, müzekker, müennes, marife, nekre, sıfat ve isim tamlamaları gibi önce cümleyi oluşturan parçaları öğretmekle öğretime başlamaktadır.

Set detaylı incelendiği zaman, iletişimsel öğrenme kuramını takip ettiği görülecektir. Hem öğrenci kitabı hem de alıştırma kitabındaki uygulamalar ve alıştırmalar öğrenci ve öğretmenin beraber çalışmasına olanak verecek niteliktedir. Setin iletişimci öğrenme kuramını benimsediğinin başka bir göstergesi de insanın günlük hayatta daha çok ihtiyaç duyduğu muzari fiili yani şimdiki zamanı, mazi fiilden daha önce ele almış olmasıdır. Zira insan geçmişteki bir zamandan çok, yaşadığı anı ifade etmek ihtiyacı duyar.

Genel Arapça setlerinde görmediğimiz başka bir özellik de bu setin daha ilk derslerinden itibaren günlük kullanımda gerekli olan kalıp ifadelere yer vermesidir ki bizce bu setin en öne çıkan özelliklerinden biridir. Çünkü bu tip yapıları gramer kitaplarından çok okuma kitaplarından öğretmen veya öğrenci kendisi çıkarır. Burada ise konulara paralel olarak, günlük hayattaki önemine binaen bu tip yapılar verilmiştir.

Başka setlerde görmediğimiz noktalardan birisi de gramer konuların yeterince ve yerinde anlatılmış ve örneklenmiş olmasıdır. Esasen bu tip bir anlayış modern dil anlayışının da bir tezahürüdür. Zira karışık dil yapıları ve anlaması zor kuralların dayatıldığı bir anlayışın yüzyıllardır başarılı olmadığı görülmüştür. Sette uzun zamandan beri eğitimcilerin üzerinde kafa yordukları dilbilgisi konularından fazlalıkların atılması konusunun gerçekleştirildiğini görmekteyiz. Kuralların kısa ve öz olarak ele alınıp, birkaç akılda kalacak güncel örnekle verilmesi bizce de yeterlidir. Gramer öğrenmenin amacı, yanlıştan kurtulup iletişimi doğru sağlamaya yardımcı olmaksa verilen bu bilgiler öğrenciye yetecektir. Fazlası öğrenci için bir yüktür.

Bizim de 1srarla üzerinde durduğumuz konulardan bir olan karşılaştırmalı öğretim yönteminin bu sette yer yer uygulandığına şahit olmaktayız. Bazı konular, örneğin sıfat tamlaması ve isim cümlesi karşılaştırmalı olarak ele alınmakta ve farklılıkları ortaya konulmaktadır. Bu yöntem kanaatimizce gramer kurallarının öğretiminde en etkili yöntemlerden biri, belki en önemlisidir. 
Setin ilerleyen derslerinde cümle tahlillerinin yapılması, öğrenilen kuralların pekişmesi açısından oldukça önemlidir. Çünkü teorik bilgi bir süre sonra unutulabilecektir. Ancak üzerinde uygulama yapılan kurallar pekişecek ve öğrencinin zihninde yer edecektir. Bu açıdan bakıldığında da setin Türkiye'de okutulan diğer öğretim setlerinden bir adım daha önde olduğu söylenebilir. Ayrıca setin gramer konularını dört beceri alıştırmalarına yaymış olması fevkalade önemlidir. Çünkü öğrenci dersin her aşamasına, o dersin dilbilgisi kuralını görecek ve duyacaktır. Bu da onun kuralı tekrar etmesine ve böylece zihnine yerleşmesine zemin hazırlamaktadır.

Ancak sette bazı aksaklıkların varlığı da bir gerçektir. Örneğin, bazı gramer terimlerinin çok erken verilmesi ve öğrencilerin bu terimler hakkında bilgi sahibi olmamaları kafalarının karışmasına neden olabilir. Öte yandan ses dosyalarının CD'de olması öğrencilerin değişik ortamlarda okuma ve dinleme parçalarına daha kolay ulaşmalarını sağlayacaktır. İştikak(Türetme) gibi bazı konuların henüz onuncu derste verilmesi kanaatimizce çok uygun olmamıştır. Çünkü öğrenci henüz o aşamada değildir. Bu konunun 14-15. derslerde verilmesi daha uygun olacaaktır. Çünkü öğrenci o ana kadar elde ettiği birikimle, bu gibi konuları daha rahat kavrayacaktır.

Aşağıda, elde ettiğimiz bulgular doğrultusunda, bahse konu olan setin tespit edebildiğimiz olumlu ve olumsuz yönleri sıralanmıştır:

\section{1-Setin Dilbilgisi Öğretimi Açısından Olumlu Yönleri}

-Konular tümevarım yöntemiyle kolaydan zora, basitten karmaşığa doğru anlatılmıştır.

-Sette sarmal öğrenme yaklaşımımetodu benimsenmiş ve uygulanmıştır.

-Özellikle fiil çekimleri konusunda acele edilmeden mazi, muzari ve emir fillerinin bazı şahıs formları verilerek tamamı verilmemiştir.

-Setin dilbilgisi konularında açık ve anlaşılır bir dille kullanılmıştır.

-Dilbilgisi konuları için yeterince açıklama yapılmıştır.

- Öğrencinin günlük hayatta kullanacağı kalıp ifadelere yer verilmiştir.

-Dilbilgisi konularına dört beceri alıştırmalarında yer verilmiştir.

-Benzer konular karşılaştırmaları olarak ayrıca ele alınarak farkları ortaya konulmuştur.

-Bir iki konu hariç konuların işıleniş sırası doğrudur.

-Dilbilgisi konusundan hemen önce o konuyla ilgili bir parça vermesi,

-Cümle tahlilleri yapıyor olması.

\section{2-Setin Dilbilgisi Öğretimi Açısından Olumsuz Yönleri}

-Dilbilgisi konularını bazı ünitelerde yoğun ve çok çeşitli işlemesi,

-Bazı konuların (izafet gibi) işlenmesinin geciktirilmesi,

-Haber çeşitlerinde mübtedayınekira kullanmak gibi birkaç konuda öğrencilerin bilmediği hiç duymadığı hususlardan örnekler verilmesi,

-Bazı konuların işlenmesinde acele edilmiştir.

Sonuç olarak, "el-Yâsemîn" Arapça öğretim setinin, birkaç husus dışında dilbilgisi konuları ve konuları ele alış yöntemi olarak başarılı olduğu değerlendirilmiştir. Özellikle setin sarmal öğrenme yaklaşımını etkili bir şekilde kullanması dikkati çekmektedir. Setin iletişimsel bir metot benimsemesi, dilbilgisi konularını işleyişine de yansımış ve güncel örnekler vererek dilbilgisi konularının pekiştirilmesi amaçlanmıştır. Konuların tam olarak bitmesi ve anlaşılması setin bütün aşamalarının bitmesiyle mümkün olacağından, bazı konuları kavramak için setin düzeylerinin 
tamamının bitmesi beklenmelidir. Çünkü setin hazırlanmasında, özelden genele ya da olaylardan yasalara geçiş şeklindeki, akıl yürütmek anlamına gelen tümevarım yöntemi benimsenmiştir. Kanaatimizce bu setin iyi bir şekilde okutulması ve buradaki dilbilgisi kurallarının güzel bir şekilde işlenmesi ek bir dilbilgisi kitabının okutulmasına gerek bırakmayacaktır.

Ayrıca setin alıştırma kitabının oluşunu çok önemli bir avantaj olarak değerlendirmek gerekir. Alıştırma kitabının ana kitaba yani öğrenci kitabına paralel olarak konuları ele alması, öğrencilerin hem motivasyonu hem de öğrendiklerini pekiştirmeleri açısından oldukça önemlidir. Kanaatimizce iyi bir programlama yapmak şartıyla Arapça hazırlık sınıflarında bu iki kitapla öğrenciler üst sınıflara çok iyi bir şekilde hazırlanabilir. Bu setin, ciltler dolusu bazı yayınların verdiğini iki kitapla vermiş olduğunu söyleyebiliriz.

\section{8. Öneriler}

"el-Yâsemîn" Arapça öğretim seti, genel olarak dilbilgisel açıdan başarılı olmakla beraber, bazı üniteleri yoğun işlemiş olması öğrenci açısından sorun teşkil edecektir. Bu açıdan bu yoğun kısımların diğer konulara dağıtılması, gerekiyorsa özellikle B1 düzeyinin son ünitelerindeki bazı konuların B2 düzeyine kaydırılmasının daha faydalı olacağı kanaatindeyim. Öte yandan bazı konuların sırasının tekrar gözden geçirilmesi ve yer değişikliği yapılması da kavrama açısından faydalı olacaktır düşüncesindeyim. Esasen Türkiye şartlarında ve Türk öğrenciler nezdinde bu ve bunun gibi setlerdeki en büyük eksiklik dilbilgisi konularının Arapça açıklanıyor olmasıdır. Dolayısıyla öncelikle bu eksikliği giderecek setlerin hazırlanmasının gerekliliğine inanıyorum. Ancak hazırlanacak yeni setlerin mutlaka iletişimsel yöntemlerle hazırlanması ve dilbilgisini amaç olmaktan çıkaran bir bakış açısıyla hazırlanması gerekir. Setin interaktif yanlarının çok olması yanında, okuma ve dinleme parçalarının yer aldığı bir CD’nin setle verilmesinde de ayrıca fayda vardır.

\section{KAYNAKÇA}

Abs, M., es-Sibai, A. el-Ebraş, M., el-Annan, M. (2013). Silsiletu'l-Lisan. İstanbul: Fatih Sultan Mehmet Üniversitesi Vakıf Üniversitesi Yayınları.

Akarsu, B. (2007). Felsefe Terimleri Sözlüğ̈̈. Ankara. İnkılap Kitabevi.

Bakırc1, S. - Demirayak, K., (2001). Arap Dili Gramer Tarihi. Erzurum: Atatürk Üniversitesi Fen Edebiyat Fakültesi Yayını.

el-Cürcani, A. M.,(ty). Tarifat. Kahire: YKY

Dağbaşı, G. (2018). Şiirle Yabancı Dil Olarak Arapça Öğretimi. TurkishStudies-International PeriodicalfortheLanguages, LiteratureandHistory of TurkıshorTurkıc Volume 13/4, Winter 2018, p. 387-402 DOI Number: http://dx.doi.org/10.7827/TurkishStudies.12883 ISSN: 13082140, ANKARA-TURKEY

Doğan, C. (1989). Arapça Öğretim Metot ve Teknikleri. Ankara: YKY

Dolunay, S. K., (2010). Dil Bilgisi Öğretiminin Amacı ve Önemi, TÜBAR-XXVII-/-Bahar, 2010, s. 275-284.

el-Fergani, A.b.M. (1986). el-Mustevfafi'n-Nahv (Tahkikli Metin, Muhammed Bedevî el-Mahtun: Muhakkik) Kahire: YKY

Galâyini, M. (1966). Camiü'd-Dürusi'l-Arabiyye. Beyrut: el-Mektebetu'l-Asriyye.

Günday, H. - Şahin Ş., (2005). Arapça Dilbilgisi, Nahiv Bilgisi. İstanbul: Alfa Yayınları. 
el-Hûlî, M.A. (2000). Arapça Öğretim Metotları (Cihaner Akçay, Çev.) Ankara: Gazi Eğitim Fakültesi Yayınları.

Kanafani M. B. (2017). el-Yâsemîn. Dubai: Al Yasameen Yayınları.

Karasar, N. (1999). Bilimsel Araştırma Yöntemi.Ankara: Nobel Yayınları.

Kaymaz, Z. (2011). Türkçenin Arapçaya Etkileri Üzerine Bazı Tespitler. TurkishStudiesInternational PeriodicalForTheLanguages, LiteratureandHistory of TurkishorTurkic Volume 6/1 Winter 2011, p. 69-73, TURKEY

Özcan, M. vd. (2016). Arap Dili Eğitiminde kullanılan Silsiletu'l-Lisan Setinin Öğrenci-Öğretmen Görüsslerine Göre Yöntemsel Açıdan Değerlendirilmesi ve Eksik Yönlerine Çözüm Önerileri. Bülent Ecevit Üniversitesi İlahiyat Fakültesi Dergisi, Cilt 3, Sayı 1, ss. 181-204

Sarmış, İ., (2005). Arapça Dilbilgisi. Konya: Esra Yayınları.

Şahâte, H. (1992). Ta'lîmu'l-Luğati'l-Arabiyyebeyne'n-Nazariyyeve't-Tatbîk. Kahire: ed-Dâru'lMisriyyeti'l-Lübnaniyye.

Yılmaz, H. (2018). Arapça Eğitiminde Gramerin Yeri ve Önemi. Sosyal Bilimlerde Yeni YönelimlerV Sempozyum Bildiri Kitabi. Talin: İnstututzaGeografiju.

\section{İnternet Siteleri}

http://www.bingol.edu.tr/ -arastirma-turleri-ve-karsilastirmali-metot.pdf

alyasameen.net 